\title{
$M$ arco Antonio de la Parra, tres décadas de teatro, 1975-2006 (Un comentario general a propósito de Chile y su clase media en los tránsitos dictadura/posdictadura, modernidad/ posmodernidad)
}

M arco Antonio de la Parra, three decades of theatre, 1975-2006 (A general commentary apropos to Chile and its middle class in transition dictatorship/ postdictatorship, modernity/postmodernity)

\section{Adolfo Albornoz Farías}

Universidad de Costa Rica, Costa Rica

E-mail: a7adolfoalbornoz@gmail.com

\section{RESUMEN}

M arco Antonio de la Parra ha cumplido, durante la temporada teatral 2006, más de tres décadas como dramaturgo, período duranteel cual ha llegado a ser uno de los más importantes autores en la historia del teatro chileno. Esteartículo ofrece una mirada panorámica sobre estos treinta años de producción dramatúrgica y teatral de M arco Antonio de la Parra, desde sus primeras obras, estrenadasal final de los años setenta einicio de los ochenta, al gunas de las cuales ya forman parte de los clásicos del teatro chileno, a la vez que han llegado a estar entre las piezas latinoamericanas más representadas en el mundo durante las últimas décadas, hasta las obras más recientes y menos conocidas del autor, muchas de las cuales aún cuentan con sólo una o ninguna versión escénica a la vez que permanecen inéditas, y con las que $\mathrm{M}$ arco Antonio de la Parra activamente se ha proyectado como dramaturgo y productor cultural para el siglo XXI.

Palabras claves: Teatro, teatro chileno, historia del teatro chileno, escritura teatral, dramaturgia, literatura dramática, artes escénicas.

\section{ABSTRACT}

M arco Antonio de la Parra has celebrated during the 2006 Theatrical Season more than three decades as a playwright. In this period he has become one of the most important 
authors in Chilean Theatre $\mathrm{H}$ istory. This article offers a panoramic view of these thirty years of $\mathrm{M}$ arco Antonio de la Parra's dramatic and theatrical production, from his first works, premiered in thelate 70's and early 80's, some of which are al ready part of C hilean Theatre Classics and have become some of the most frequently staged Latin American plays world wide during the last decades, up to the author's newest and lesser known plays, many of which still have only one or no stage version and/or remain unpublished, all of which have actively projected $\mathrm{M}$ arco Antonio de la Parra as a playwright and a cultural producer for the XXI century.

Keywords: Theatre, chilean theatre, chilean theatre history, playwriting, dramaturgy, dramatic literature, performing arts.

Recibido: 21-09-2006. Aceptado: 22-11-2006.

\section{INTRODUCCION}

- AN transcurrido treinta años desde que, en 1975, M arco Antonio de la

- Parra emergiera en el devenir del teatro profesional chileno. Ese año obtuvo, por $\mathrm{M}$ atatangos, disparen sobre $\mathrm{El}$ zorzal, una $\mathrm{M}$ ención H onrosa en el Concurso de $D$ ramaturgia de la Universidad de Chile-cuyo lugar ganador fue declarado desierto.

Tres décadas más tarde, a propósito de la presencia y vigencia del autor sobre los escenarios de Chile y el mundo, considérese, por ejemplo, que en el país, durante esta temporada 2006, mientras el Teatro $\mathrm{N}$ acional C hileno ha estrenado su más reciente obra, El teatro, la escena secreta, y el colectivo independiente Arte Facto ha llevado a escena otra de sus últimas piezas, W ittgenstein, el último filósofo, la Escuela deTeatro de la U niversidad C atólica ha mostrado el resultado de un laboratorio teatral en base a otro nuevo texto del dramaturgo, La cruzada de los niños, por su parte, M arco Antonio de la Parra ha subido a escena para protagonizar otra de sus más recientes creaciones, El Licenciado Vidriera o el loco de Cervantes, y paralelamente ha colaborado en la dramaturgia de T he Winners, obra concebida colectivamente de acuerdo a los intereses de un grupo de actores; a la vez, en el extranjero, también durante este año 2006, mientras en España las compañías Blenamiboá y EI T inglao se han unido para estrenar D ecapitation, en Costa Rica la Compañía N acional de Teatro ha llevado a escena La puta madre o la tierra insomne.

Así, este artículo viene a dar cuenta de modo panorámico e integrador del trabajo de uno de los dramaturgos chilenos de más sostenida, extensa y variada producción en la historia del teatro nacional y uno de los de mayor proyección internacional. 


\section{TRES DECADAS, TRES PERIOD OS DE PRODUCCION, TRES PROYECTOS DE IN VEST IGACION}

La producción dramatúrgica de M arco Antonio de la Parra, queya suma al rede dor de cincuenta títulos, puede estructurarse en torno a dos criterios fundamentales, uno cronológico y otro poético.

D esde la perspectiva temporal, su teatro se organiza en tres períodos. El primero se inicia con la premiación, en 1975, y el estreno, en 1978, de su obra inaugural, M atatangos, disparen sobreEl zorzal, y abarca prácticamentetodas las piezas escritas, llevadas a escena o publicadas, en el contexto de la dictadura militar chilena. Entre las obras más emblemáticas de este período destacan Lo crudo, lo cocido, lo podrido (1978), una de las producciones culturales chilenas más representativas de la época, incesantemente visitada por estudiosos nacionales y extranjeros que han dado lugar a una importante cantidad de estudios críticos, y La secreta obscenidad de cada día (1984), una de las piezas latinoamericanas más representadas y traducidas en el mundo durantelas últimas décadas (de la Parra, 1983, 1988).

La segunda etapa de producción dramatúrgica comienza hacia el final del Gobierno militar, apareciendo King K ong Palace o el exilio deTarzán y D ostoievski va a la playa, publicadas en 1990, como las obras detránsito hacia este segundo período, el que se prolonga durante los primeros años de transición a la democracia y en el que sobresalen, por ejemplo, piezas galardonadas internacionalmente como El padremuerto (1991) y Tristán el solda (1993) (de la Parra 1990, 1992, 1994a, 1994b).

El tercer período en este devenir teatral se inicia con la escritura, en 1994, de El continente negro, O felia o la madre muerta y La pequeña historia de Chile, estrenadas durante esa misma temporada o las siguientes, y abarca todas las obras escritas, llevadas a escena o publicadas, en el marco de la posdictadura chilena. Esos y otros de los trabajos más representativos de este período, como La puta madre (1997) y M onogamia (2000), han destacado relevándose en la ocupación de un lugar casi siempre central en la cartelera teatral nacional y no pocas veces en algunos circuitosinternacionales (de la Parra, 1995b, 1998, 1999).

D esdela perspectiva temática, la producción teatral de M arco Antonio dela Parra se organiza en torno a tres indagaciones sustanciales. La primera guarda relación con la permanente revisión de la historia y la identidad chilena, especialmente en su contexto republicano y moderno. El imaginario nacional, sus relatos y mitos, referentes e íconos, y su memoria, han sido preferentemente examinados en Lo crudo, lo cocido, lo podrido (1978), pasando por La pequeña historia de Chile (1994) y llegando hasta Las costureras (2000), entre otras obras. 
El segundo proyecto de investigación dice relación con el incesante asedio a la subjetividad de la clase media chilena de final del siglo XX e inicio del XXI. Las principales tensiones de esta clase, sus amores y odios, lealtades y traiciones, sus determinantes políticas y económicas, han sido particularmente abordadas, por ejemplo, en Infieles(1988), El continentenegro (1994), M onogamia (2000) y Sushi (2003).

La tercera obsesión ha sido la permanente apropiación y resemantización, desde el Chile finisecular, de muchos de los principales íconos culturales occidentales. M arx y Freud, Tarzán y M andrake, N eruda y D ostoievski, Shakespeare y Cervantes, Pinochet y Bush, la tragedia griega y los reality show, la high tech y el sushi, la guerra y los mass media, etc., han sido recogidos y reelaborados desde M atatangos, disparen sobre El zorzal (1975), pasando por La secreta obscenidad de cada día (1984), King Kong Palace o el exilio de Tarzán (1990) y M adrid/ Sarajevo (1999), hasta W ittgenstein, el último filósofo (2004), entre muchas otras piezas.

Por cierto, a diferencia de la clasificación cronológica, donde los límites aparecen más definidos y las consiguientes separaciones más claras, este ordenamiento poético no supone una distinción rígida al interior de la producción de $M$ arco Antonio de la Parra y más bien sugiere ciertos énfasis siempre movedizos. Así, por ejemplo, las tres líneas de investigación han compartido, como vaso comunicante, una permanente referencia y eventual reflexión a propósito del poder, sus mecanismos y relaciones, como categoría y realidad fundamental para la interacción y la convivencia humana. A la vez, una obra como La secreta obscenidad de cada día, cuyo gesto más evidente pareciera ser la revisión de referentes basales del pensamiento teórico y político moderno, como $\mathrm{M}$ arx y Freud, es también una mirada a la sociedad chilena en el contexto de la dictadura militar, mientras que una pieza como La puta madre, cuya tematización central pareciera ser el devenir sociopolítico chileno en el tránsito democracia-dictadura-posdictadura, es a la vez la reescritura de un relato fundacional de la cultura occidental, La O restiada.

\section{Primer período, dictadura y crisis de la modernidad, 1975-1988}

El primer período de producción dramatúrgica de M arco Antonio de la Parra, desde el estreno, en 1978, de M atatangos, disparen sobre El zorzal, dirigida por O scar Stuardo para el Grupo de Teatro del Instituto Goethe, y Lo crudo, lo cocido, lo podrido, dirigida por G ustavo M eza y llevaba a escena junto al Teatro Imagen, hasta el estreno, en 1988, de Infieles, producida y dirigida colectivamente por el Teatro de la Pasión Inextinguible bajo la supervisión del autor, se 
caracteriza por tres aspectos fundamentales: el complejo marco político y cultural que determina la llegada del dramaturgo a la escena teatral chilena, su dinámica y versátil instalación al interior del campo teatral nacional de esos años, y la clara y fundacional definición que en ese contexto hace de sus principales intereses poéticos y discursivos.

A propósito del marco político y cultural dela época, biográficamente, $\mathrm{M}$ arco Antonio de la Parra, nacido en 1952, forma parte de aquella generación de chilenos que, tras el Golpe de Estado del 11 de septiembre de 1973, tuvo que enfrentar y resolver el tránsito hacia su adultez como correlato a la instalación y desarrollo del autoritarismo político y del liberalismo económico en el país. Laboralmente, el dramaturgo (además narrador, ensayista y guionista), cuya primaria formación y actividad es como médico psiquiatra, a la vez que ha incursionado en la publicidad, los medios de comunicación y la docencia, entre otras actividades, pertenece a aquella subgeneración de compatriotas que debió elaborar su crecimiento, desarrollo y prosperidad en un contexto eventualmente reñido con sus convicciones personales, pero a la vez atractivo en cuanto a posibilidades y realizaciones materiales. Artísticamente, el autor integra aquella primera generación de creadores nacional es que, tras al gunos años de relativo apagón cultural durante el inicio de la dictadura, logró articular un heterogéneo coro de voces críticas - disidentes, resistentes, contestatarias o refractarias- al gobierno militar.

En el teatro, M arco Antonio de la Parra comparte el escenario posgolpe con otros dramaturgos que también contribuyeron a renovar los registros de la escritura teatral chilena, como D avid Benavente (Pedro, Juan y Diego, 1976), Luis Rivano (TellamabasRosi cler, 1976), G ustavo M eza (El último tren, 1978) y Juan Radrigán (Testimonio de lasmuertes deSabina, 1979), entre otros; y con directores, actores y diseñadores que tras la clausura -intervención o cierre- por parte del autoritarismo del proyecto de desarrollo cultural nacional impulsado hasta 1973 por los teatros universitarios - proyecto del que habían sido parte y eran herederos- , lograron reinventarse fuera del circuito institucional a través de nuevas compañías independientes, como Teatro La Feria, dirigido por Jaime Vadell (H ojas de Parra, 1977), Teatro Imagen, dirigido por G ustavo M eza (Lo crudo, Io cocido, lo podrido, 1978) y Taller de Investigación Teatral, dirigido por Raúl O sorio (Tres M arías y una Rosa, 1979), entre otras.

Todos o la mayoría de ellos, de una u otra forma, en el texto y/o en la escena, tendieron a tematizar el colapso de los proyectos históricos individuales y colectivos, la perplejidad y frustración consecuentes y la evidente incertidumbre, relativa esperanza o definitiva desesperanza frente al futuro. Todos o la mayoría de ellos, además, tendieron a asumir el hecho teatral con urgencia, reval orizando su potencial dialógico rápido y directo para con el espectador y la comuni- 
dad, especialmente en condiciones de censura, autocensura y represión. A propósito de la opción trabajada por M arco Antonio de la Parra, éste señalaría: "La dictadura obligaba a crear lenguaje para lo que ella misma prohibía, obligaba al espacio posible a volverse depositario de lo irrepresentable" (1994c: 36).

En el campo teatral de la época, su quehacer primeramente se distingue por los singulares y variados caminos por medio de los cual es irrumpe en y se vincula con el mundo artístico y cultural profesional. M arco Antonio de la Parra se inició en la actividad teatral en general y como aficionado al comienzo de los años setenta, mientras realizaba sus estudios superiores en la Facultad de $M$ edicina de la U niversidad de Chile y paralelamente asistía a talleres de teatro en la Escuela de Artes de la C omunicación de la U niversidad C atólica; y su "prehistoria dramatúrgica", es decir, la etapa de sus primeros ejercicios autorales, tuvo lugar entre 1974 y 1977, en la Facultad de M edicina y con la Asociación Cultural Universitaria, ambas de la U niversidad de Chile.

En consecuencia, su primera figuración en el circuito escénico profesional, M atatangos, disparen sobre El zorzal (1975), correspondió a su más acabado escrito de su etapa amateur, con el que algunos años más tarde consiguió la atención de 0 scar Stuardo, uno de los creadores más singulares del teatro chileno contemporáneo - para algunos "de culto"-, tanto por su innovación frente a los modelos escénicos hegemónicos en ese momento como por la marginalidad del mismo aporte. Para el dramaturgo esta primera experiencia consistió en proveer el texto sin participar mayormente del proceso de producción. Por el contrario, su segundo aunque prácticamente paral elo trabajo en la escena profesional, Lo crudo, lo cocido, lo podrido, estrenado también en 1978, correspondió a su primer proyecto con intencionalidad claramente profesionalizante, con el queconcitó el interés de G ustavo M eza, uno de los directores de más dilatada y significativa trayectoria en la historia del teatro chileno, cuyo quehacer en esemomento fue particularmente trascendente para la reconstitución de la escena teatral nacional luego de su dislocamiento por efecto de la dictadura, por ejemplo, al estrenar junto al Teatro Imagen, además del texto fundacional de M arco Antonio de la Parra, varias óperas primas de otros autores nacionales igualmente debutantes, como Luis Rivano (TellamabasRosicler, 1976), Andrés Pizarro (Tres mil pal omas y un loro, 1977), Juan Radrigán (Testimonio de las muertes de Sabina, 1979), y su propio primer texto (El último tren, 1978). Para M arco Antonio de la Parra esta experiencia sí implicó un ejercicio de escritura en diálogo con el trabajo escénico, a la vez que una escuela en términos de autoría teatral:

H ice una y otra versión hasta lograr lo que G ustavo consideró un material de trabajo... Con él aprendía a cada momento algo nuevo que me iba iluminando lo que significaba, realmente, ser dramaturgo (1988: 30). 
junto a él, en largas sesiones de lectura y discusión, paseos peripatéticos, ensayos meticulosos, fui entendiendo de qué se trataba esto de la dramaturgia. Escribí con su mirada de padre por encima demi hombro, dejando queyo me manifestara en toda mi plenitud (1995d: 5).

Gustavo me hace entender lo que significa el arte de la escritura, y lo hace de una forma muy bonita; él nunca me enseñó a escribir, sino que estrujó mi propia forma de hacerlo (cit. por Guerrero, 2001: 89).

L o crudo, lo cocido, lo podrido además proporcionó a su autor una visibilidad mucho mayor a la normalmente recibida por un dramaturgo debutante, por ejemplo, en comparación a los otros autores nacionales simultáneamenteemergentes; primero, porque representó el arribo de la dramaturgia chilena contemporánea, es decir, pos 1973, al repertorio de un teatro universitario - específicamente al de la U niversidad Católica- , luego de que éstos fuesen intervenidos o cerrados tras el golpe de Estado; segundo, debido a que el montaje sólo alcanzó a ser preestrenado y visto por al rededor de cuarenta personas, tras lo cual fue censurado como producción institucional por los representantes del G obierno militar al interior de la casa de estudios; tercero, porque su director, Gustavo M eza, resistió y contestó a la dictadura - arrastrando en esta empresa al autor- al asumir el riesgo de igualmente estrenar la obra durante esa misma temporada, aunque junto a otro elenco y bajo el sello de su propia compañía, el Teatro I magen; y cuarto, debido a queal año siguiente, 1979, el texto obtuvo, compartido, el Premio del Latin American Theatre, en N ueva York.

Esta repentina y vertiginosa notoriedad contribuyó a la rápida acogida del novel autor por parte de los teatristas nacionales; N issim Sharim y D elfina Guzmán lo invitaron a trabajar con el Teatro Ictus, agrupación precursora en el país en materia de creación colectiva y emblemática en ese momento dentro de la actividad cultural de oposición, lo que se tradujo en la co-autoría de dos producciones, Lindo país esquina con vista al mar (1979) y La mar estaba serena (1980), ambas dirigidas por Claudio Di G irolamo; tras lo cual recibió otra invitación, esta vez de Raúl 0 sorio, director de otro de los colectivos paradigmáticos del teatro contestatario, el Taller de Investigación Teatral, proyecto que fue iniciado, pero quesin embargo no prosperó. Algún tiempo más tarde, ya validado por sus nuevos pares, $M$ arco Antonio de la Parra daría el paso hacia la gestión de sus propias producciones escribiendo, dirigiendo y protagonizando La secreta obscenidad de cada día (1984), su más reconocida obra, con la que volvería a escena una y otra vez, dentro y fuera del país, durante casi tres años, hasta el estreno de sus próximos trabajos, El deseo de toda ciudadana (1987), dirigido por Ramón G riffero - cuya versión narrativa ganó ese mismo año el Concurso de $N$ ovela de Ediciones $O$ rnitorrinco- , el nfieles (1988), dirigido colectivamen- 
te bajo la supervisión del autor, y por el que recibió el Premio de la Asociación de Periodistas de Espectáculos a la M ejor D ramaturgia de la temporada; luciendo, en síntesis, como una de las voces teatrales - y literarias- más destacadas y singulares de entre las surgidas en Chile durante los años de la dictadura militar.

A propósito de los énfasis poéticos y discursivos en la dramaturgia de $M$ arco Antonio de la Parra, destaca el significativo cuestionamiento que sus obras representaron frente al campo cultural en el que se inscribían, determinado por férreos binarismos como oficialismo/oposición, apelando a una insistente y a veces desestabilizadora ambigüedad. ¿Era $M$ atatangos, disparen sobre EI zorzal un homenaje 0 una parodia a Carlos $G$ ardel - y a través de él a una narración hegemónica de lo latinoamericano? ¿C riticaba L o crudo, lo cocido, lo podrido el presente $o$ el pasado nacional, el poder autoritario militar o la tradición democrática republicana? ¿Se referían sus indagaciones y críticas específicamente al país, al continente 0 a todo occidente? A la vez, tanto ese par de piezas fundacionales como las siguientes también se distinguieron por poner a prueba las categorías establecidas por la teoría dramática y literaria en el contexto chileno y latinoamericano de esos años. ¿Se trataba de un autor (camufladamente) realista, del absurdo o grotesco?

En el caso de las obras que más explícitamente tematizaban la realidad nacional, como Lo crudo, lo cocido, lo podrido y EI deseo detoda ci udadana, la crítica chilena de la época transitó desde enfoques que enfatizaron la emergencia de una dramaturgia distante del realismo tradicional y dominante en el teatro na cional, valorando una mirada al país desde claves ambiguas y no racionales, carente de referentes específicos, cercana a las lógicas narrativas del ritual, la pesadilla y el deseo (Piña, 1983, 1998b), hasta perspectivas que, aun reconociendo el formal distanciamiento del realismo, insistieron en destacar una crítica directa y concreta al poder dictatorial en un intento por clausurar sus fórmulas discursivas autoritarias y represivas (Vidal, 1982). En el caso de las piezas que más abiertamente dialogaban con la cultura occidental, como $\mathrm{M}$ atatangos, disparen sobre El zorzal y La secreta obscenidad de cada día, los comentaristas nacionales del momento se movieron entre rescatar un ambiguo desmontaje y desacralización de algunos de los íconos, y su proceso de construcción, más preciados de y por la cultura popular (Piña, 1998a), hasta enfatizar un directo y crudo ajuste de cuentas con algunos de los principales relatos y dogmas, sus paradojas y contradicciones, del siglo XX (Ulibarri, 1999). El marcado carácter polisémico de este teatro también fue visto como un recurso para generar complicidad descifratoria e interpretativa entre el escenario y la platea, de modo de articular un espacio de comunidad y comunión vitalmente necesario durante los años de la dictadura (H urtado, 1992). 
Un momento de inflexión en este trayecto dramatúrgico se produjo con Infieles (1988), obra con la cual el autor inaugura su tercera línea de investigación, la subjetividad de la clase media chilena finisecular, trabajada en forma más íntima y realista que sus otros dos proyectos autorales, y con la que además completa y cierra la primera etapa de su producción. En palabras del dramaturgo:

Surgió Infieles, mezcla de dos ideas. Por un lado, la culpa de una generación que sobrevivía exitosamente en un país tan ajeno a sus ideales y sus principios, en una moral que estaba lejos de ser la deseada... Por otra parte, la relación de los amantes, la otra cara de las infidelidades, el dolor, el sufrimiento que toda pasión lleva inmerso en su propia significación;

enfatizando, en ese momento:

Infieleses lo más doloroso quehe escrito. Estoda nuestra generación, la queno pudo ser, la que truncó sus sueños y anhelos, la que más se ha equivocado. La que no le quedó otra que equivocarse. La responsable del futuro (1988: 54-56).

En general, los personajes que dan vida al primer teatro de $M$ arco Antonio de la Parra dan cuenta de una escena poscatástrofe, pero sin haber sido, en su individualidad, necesariamente arrasados o devastados por ésta. M úsicos venidos a menos, garzones que conocieron tiempos mejores, ex militantes de partidos o movimientos deizquierda, funcionarios de dictaduras de derecha, secretarias y empleados, profesionales que se ganan la vida en forma diferente a lo que al guna vez soñaron o imaginaron, pequeños perversos burgueses, etc., no representan a los marginados o excluidos por el sistema político-económico, ni a las otredades invisibilizadas o perseguidas por el entramado sociocultural y mucho menos a quienes detentan el poder o son sus principal es beneficiarios. Se trata, en cambio, de aquellos que en su medianía y cotidianidad se mueven entre el amor y el odio, la lealtad y la traición, el sometimiento y la emancipación, siempreen un tono menor, sin heroísmo ni estridencia, y así consiguen trabajos y los pierden, se enamoran, tienen hijos y se separan, logran cierta estabilidad 0 prosperidad, aunque siempre volátil, etc., en un mundo que probablemente no comprenden a cabalidad o con el que no necesariamente concuerdan, pero en cuyos pliegues aprenden a sobrevivir a medio camino entre la culpa, la resignación y la satisfacción; la nostal gia, la perplejidad y, a veces, cierta esperanza.

D icha tematización, de núcleo fuertemente localizado y habitualmente doloroso, es pasada por el cedazo formal de una teatralidad mayoritariamente delirante, pero no incoherente ni críptica, que invita a lo sorpresivo, cuya estructuración dramática usualmente construye, avanza y deconstruye su propio an- 
dar, de modo que toda certeza deviene transitoria y es puesta en jaque por los mismos materiales o evidencias que la posibilitan, con una lógica narrativa que simultáneamente devela y oculta, y dondefinal mente personajes y trama, acciones y discursos, existen y se explican por su natural eza teatral, como una especie de mundo paralelo, y no en tanto fiel representación o mímesis de la realidad. Setrata de un teatro que entrega más dudas que respuestas y que en ningún caso explica o informa, que desconfía del mundo aparente y que no presta excesiva atención a la realidad tal como se presenta sino en tanto síntoma - o código- de al go más profundo que es necesario descubrir - o descifrar. Así, el escepticismo y el cinismo, la ironía y el humor negro que a primera vista caracterizan esta particular mirada al estado de las cosas en el Chile del momento, suelen encubrir una profunda fractura emocional e intelectual.

A la vez, los personajes que representan a otros personajes, las situaciones que se transforman en otras situaciones, citas y suplantaciones, sutiles referencias y explícitos diálogos intertextuales, el cruce entre figuras e historias de la realidad y de la ficción, así como diversos otros recursos, junto con desafiar ciertas convenciones representacionales (realistas) del espectador nacional de la época, interrumpen la lógica del ordenamiento espacio-temporal cotidiano, emergiendo así al gunos de los principal es e históricos relatos, creencias y mitos de la chilenidad de clase media un espectro en permanente contraste y/o ajuste de cuentas con el presente nacional.

Finalmente, esta singular reconstrucción dramatúrgica del Chile de los setenta y ochenta además recibe el eco del reordenamiento político y epistémico que simultáneamente está ocurriendo en el mundo, apareciendo las problemá ticas locales, en sus dimensiones colectivas e individuales, públicas y privadas, en diálogo con un patrimonio cultural "universal" - por lo menos, occidentalsobre el cual también se reclama pertenencia. Así, M arco Antonio de la Parra, al comenzar a fundir materiales, lenguajes y recursos sin importar su origen 0 identidad - tópico todavía fundamental en el pensamiento crítico latinoamericano hegemónico hasta los años setenta- sino en función de sus potencialidades expresivas, emerge como un autor culto, cosmopolita y posmoderno, cuya mirada a su entorno inmediato, el Chile de la dictadura, también participa del espíritu de su época en el más amplio sentido, el naufragio de la modernidad.

\section{Segundo período, transición, perplejidad e incertidumbre, 1989-1994}

El final de la dictadura militar y el inicio de la transición y reconstrucción de mocrática, conducida a partir del 11 de marzo de 1990 por los gobiernos de la Concertación, influyen fuerte aunque heterogéneamente en muchos delos crea- 
dores chilenos más significativos de los años setenta y ochenta, por ejemplo, llevando a al gunos de los dramaturgos de mayor actividad durante dicho período al autismo o mutismo hacia el inicio de la nueva década.

En el caso de M arco Antonio de la Parra, sin embargo, con el comienzo dela transición, por una parte, el ritmo y volumen de su producción seincrementan: si entre 1978 y 1988 produjo cinco obras de autoría individual, durante los cinco años siguientes dará a luz alrededor de diez nuevos textos teatrales. Por otra parte, esta vertiginosa nueva etapa, iniciada con la escritura, entre 1989 y 1990, de King Kong Palace o el exilio deTarzán y D ostoi evski va a la playa, y una nueva colaboración en una creación colectiva, La noche de los volantines, estrenada en 1989 por el Teatro I ctus y bajo la dirección de N issim Sharim, conlleva la interrupción y dislocación, en la forma y en el fondo, del proyecto teatral desarrollado hasta ese momento - el que será retomado por el autor a partir de 1994, es decir, en su tercer período de producción.

En primer lugar, tras diez años de gradual y casi intuitivo delineamiento de tres grandes líneas de investigación, a saber, la historia e identidad chilena, la subjetividad de la clase media nacional y los grandes íconos culturales occidentales, abordadas desde un desplazamiento desde el realismo mimético tradicional hacia la teatralización de la representación escénica, aunque manteniendo un anclaje en recursos del teatro popular; esta segunda etapa en la producción de $\mathrm{M}$ arco Antonio de la Parra aparece mucho más autoconsciente en términos poéticos, programáticamente experimental y sustentada de modo determinante en el diálogo intertextual. Por ejemplo, mientras King Kong Palace o el exilio de Tarzán (1989) especula audazmente sobre los últimos días del dictador chileno y su familia - o de un dictador tercer mundista cualquiera- luego de abandonar el poder, la obra también se apropia de personajes de ficción como Tarzán, Jane, Boy, King K ong y $M$ andrake, refiere a figuras históricas como I melda M arcos, revisa ideologías como la D octrina de Seguridad N acional, el A partheid, el neoliberalismo de los Chicago Boys y el consumismo de los nuevos ricos, reescribe y/o parodia tragedias isabelinas como $\mathrm{H}$ amlet, $\mathrm{M}$ acbeth, $\mathrm{O}$ tel 0 y Romeo y Julieta, cita tragedias griegas como Edipo Rey, comenta la forma como dichos textos clásicos son traducidos contemporáneamente para público masivo, entre numerosas operaciones más, dando lugar a una propuesta de pastiche kitsch y neobarroco de lecturas casi infinitas.

A partir de ahí y a través de D ostoi evski va a la playa (1990), pasando por El padre muerto - una reescritura de Hamlet- (1991), D édalus en el vientre de la bestia o D édalus/Subamérica (1992), Telémaco/Subeuropa o EI padreausente(1993) y hasta H eroína (1994), entre otras piezas, crecientemente se va desdibujando la distinción entrelos énfasis temáticos previamente perfilados - cuyas fronterasya eran naturalmente movedizas- para fundirlos en una nueva total idad discursi va, 
a veces un tanto informe, en la que apremia la necesidad de cubrir simultáneamente diversos frentes para dar cuenta de múltiples problemáticas a la vez. Así, en comparación al período anterior, el comentario sobre la realidad nacional va difuminándose a través de un discurso más fragmentado y oblicuo - aunque, por ejemplo, en D ostoievski va a la playa un detective debe enfrentar el dolorosamente reconocible caso de cadáveres que aparecen por más que se ha intentado hacerlos desaparecer- , a medida que va intensificándose la referencia al reordenamiento político y epistémico internacional, en esos años signado por el fin de las utopías, el fin de la guerra fría, el fin de la historia, la caída del M uro de Berlín -y de todos los muros-, el fracaso de los socialismos reales-y el triunfo del capitalismo-, la desintegración de la Unión Soviética, las nuevas guerras regionales, la posmodernidad, el neoliberalismo y la globalización; esbozándose así un teatro chileno pensado también en y para el mundo.

D e todos modos, dicho gesto, por cierto subrayado en estas nuevas producciones, ya había sido anunciado durante el primer período. Por ello, el excesivo énfasis dado por lecturas formuladas en los años noventa a la aparente ambigüedad y evidente intertextualidad de las piezas inaugurales como recursos para evadir la censura (D íaz-O rtiz, 1996; Sentis, 1998; Seda, 2000), tendió a minimizar la evidencia de una dramaturgia que desde sus inicios buscó referirsea, y/o hacerse cargo de, múltiples objetos de estudio a la vez. D onde el contrabando discursivo a través de personajes e historias previamente existentes y aceptados y supuestamenteneutral izados por sus contextos de origen, así como la operación general de decir una cosa para hablar de otra, junto con ser efectivos mecanismos de autocensura para evadir a la eventual censura, daban cuenta de una producción cultural más refractaria que contestataria y que por lo mismo mantuvo su carácter marcadamente polisémico cuando la dictadura hubo acabado. Así, por ejemplo, en medio de las infinitas prácticas y discursos que alrededor de 1992 eclipsaron el campo intelectual internacional para revisar, celebrar o lamentar los quinientos años de América, el dramaturgo enfatizó su distancia con las retóricas representacionales de lo latinoamericano más o menos tradicionales y/o hegemónicas, es decir, en claveindigenista, macondista o folclórica, en formato de retablo, estampa o postal, las que de una u otra forma tiñeron mucha de la producción en torno a dicha efeméride; para subrayar, en cambio, la inscripción occidental, posmoderna y global, a la vez que borroneada, fragmentada y oblicua, de su aproximación a lo nacional y a lo continental.

En segundo lugar, si durante sus primeros diez años de quehacer escénico M arco Antonio de la Parra gradualmente había ido recibiendo cierta atención desde más allá de las fronteras nacionales, es a partir de esta segunda etapa que la comunidad artística internacional comienza a interesarse por insertar la producción de éste en sus propios circuitos culturales. Por ejemplo, en Estados 
Unidos se traduce y estrena La secreta obscenidad de cada día, en Cleveland, en 1988, e Infieles, en D enver, en 1989, y lo mismo ocurre en Francia con King Kong Palace o el exilio deTarzán, en París, en 1992, entreotras realizaciones en el hemisferio norte, mientras éstas y otras piezas son también llevadas a escena en diversas ciudades de Latinoamérica; la dramaturgia del autor también es traducida y publicada en Alemania a partir de 1987, en Estados U nidos desde 1988 y en España a partir de 1991, entre otros países e idiomas; y sus nuevos textos comienzan a recibir diversos reconocimientos internacionales, como El padre muerto, Premio Borne, España, 1991, y Tristán el solda, Premio deTeatro Breve, España, 1993. En dicho contexto, no resulta un dato menor la designación del dramaturgo como Agregado Cultural de la Embajada de C hile en España entre 1990 y 1993, lo que conllevó que un autor que desde su aparición había recibido y/ o convivido con etiquetas como "independiente" o "deoposición", depronto pasara a la trinchera del oficialismo.

En tercer lugar, se produce un importante desplazamiento desde los referentes teatrales que más influyeron en el teatro de $M$ arco Antonio de la Parra durante su primer período de producción, a aquellos nuevos modelos escénicos que lo determinan en esta segunda etapa. Su primera dramaturgia da clara cuenta de la influencia de aquellos directores y compañías que durante la segunda mitad de los setenta protagonizaron la recomposición de la escena teatral chilena posgolpe, a saber, Teatro Imagen de Gustavo M eza, Teatro La Feria de Jaime Vadell, Taller de Investigación Teatral de Raúl 0 sorio y Teatro Ictus, entre otros, quienes reelaboraron el aporte de los teatros universitarios en el marco del teatro independiente y de oposición, por ejemplo, impulsando, tal como antes habían hecho los conjuntos de las casas de estudio, a una nueva generación de dramaturgosnacionales, como M arco Antonio dela Parra, Juan Radrigán, Luis R ivano, Gustavo M eza y quienes paralelamente crearon en forma colectiva, sobre cuya escritura se sustentó buena parte del teatro chileno durante la dictadura. La dramaturgia del segundo período, en cambio, da cuenta del profundo efecto que sobre ésta tuvo aquella nueva generación de directores y colectivos, como Teatro Fin deSiglo, dirigido por Ramón G riffero (Cinema U toppia, 1985), G ran Circo Teatro, dirigido por Andrés Pérez (La negra Ester, 1988), Teatro La M emoria, dirigido por Alfredo Castro (La manzana de Adán, 1989), Teatro La Troppa (Pinocchio, 1990) y Teatro del Silencio, dirigido por M auricio Celedón (M alasangre, 1991), entre otros, quienes desde la segunda mitad de los años ochenta lideraron la renovación de la escena teatral de la transición, ya desconectados del proyecto de los teatros universitarios - cuya clausura, después de una década de intensas transformaciones socioculturales ya no era un problema coyuntural sino una situación históricamente decidida- y en abierta incomodidad con el agotado campo cultural oficialismo/oposición; su quehacer, contraria 
mente a lo realizado por las generaciones anteriores, puso en decidido jaque a la dramaturgia nacional al emancipar al teatro chileno de su tradicional subordinación a la literatura dramática.

En consecuencia, si la dramaturgia del primer período de $\mathrm{M}$ arco Antonio de la Parra proponía un teatro económico en términos de recursos materiales, donde el escenario no mutaba y sobre el que se desarrollaba una narración relativamentelineal, aunque apelando a escenas cortas y rápidas, y en el que se apostaba por el trabajo interpretativo del actor, y su propia dramaturgia, como articulador de una experiencia teatral que buscaba formas de empatía directas y eficaces para con el espectador; las obras del segundo período, en cambio, reivindicaron la importancia del espacio escénico y del diseño, multiplicando las locaciones, fragmentando y complejizando las estructuras narrativas, apelando al cuerpo y la imagen como constructores de sentido, y apostando por el trabajo creativo del director como constructor de la experiencia escénica a partir de una dramaturgia que ofrecía resistencia y desafiaba a la escena, a la vez que exigía la cooperación interpretativa del espectador - proceso del que el autor estaba plenamente consciente (de la Parra, 1995a).

Por último, en dicho contexto este teatro fue renunciando a buena partedel humor y/o la ironía que caracterizaron las primeras obras del dramaturgo, emergiendo una escritura/palabra teatral más oscura y dura, que reemplazaba el lenguaje coloquial y desinhibido por uno de crudo lirismo, donde la frase corta dominaba y desafiaba, en su síntesis, al cuerpo del actor y a la materialidad dela escena a exceder y completar las posibilidades de esta palabra contraída. Luego, la pluralidad de nuevos recursos expresivos admitidos y exigidos superaba ampliamente al logos verbal y al ludus actoral sobre los que básicamente se sostuvo la teatralidad del primer período.

Y es en medio de esta búsqueda formal, tras diecisiete años de dictadura militar en Chile y en el marco de un radical reordenamiento internacional, que el comentario sobre el estado de las cosas en el país comienza a dar cuenta de un presente - es decir: temerosa transición, dudosa democracia, tormentosa modernidad, confusa nacionalidad, problemática identidad, etc.- que aparececada vez más como una mala versión de lo realmente deseado. Sin embargo, los problemas, conflictos, limitaciones y frustraciones que signan negativamente esta realidad, en sus dimensiones pública y privada, colectiva e individual, dejan de entenderse y/o explicarse sólo en función de variables coyunturales-entre otras, la dictadura- para comenzar a evidenciarse, por el contrario, como elementos quizás permanentes y/o constituyentes de la (¿nueva?) chilenidad, cuyos parámetros tradicionales, por ejemplo, de convivencia - reales o imaginarios-, definitivamente han sido superados, pero sin que haya claro consenso aún sobre 
cuáles habrán de reemplazarlos. Y es en función de ese desgarro y sus efectos sobre la subjetividad de la clase media chilena que M arco Antonio de la Parra cierra esta segunda y experimental etapa de su producción para retomar las directrices del proyecto perfilado durante sus inicios en la escritura teatral. Tal como reflexionaría el autor en ese momento:

\begin{abstract}
N ada es más claro que se ha cumplido un ciclo y que se entra en otro. El teatro de imagen, señero, totipotente, invasivo, herencia del auge de los medios de repetición audiovisuales y de cierta desazón ante la incertidumbre de todo discurso, había expulsado toda literatura del teatro, casi toda referencia a la palabra escrita y parecía deslizarse más cerca de la danza y de la música, de una experiencia más primaria que de la razón, la poesía y la consigna, donde tal vez anduvo demasiado tiempo liado. Los grandes espectáculos tuvieron su auge en Chile en los momentos de la transición democrática, cuando ya la denuncia no podía habitar la escena con la misma carga ni el mismo acento, cuando el futuro era imprevisible y más una sensación que un concepto... Signo de los tiempos, la situación hoy se revierte y la pregunta ética, sentada en el horizonte del fin de siglo... activa de nuevo la función de la palabra en la escena... (Aunque) La consolidación del director como pieza maestra de la nueva manera de entender la puesta en escena como creación en sí y no como mera interpretación, ha obligado al autor a ponerse a sí mismo en jaque y replantearse qué significa escribir... (1994d: 94).
\end{abstract}

\title{
Tercer período, posdictadura y posmodernidad, 1994-2006...
}

El tercer período de producción teatral de M arco Antonio de la Parra, desde la escritura, en 1994, deEl continente negro, 0 felia o la madremuerta y La pequeña historia de Chile, la primera producida independientemente ese mismo año y dirigida por Paulina G arcía, y las otras dos seleccionadas en la I y II M uestra de D ramaturgia $\mathrm{N}$ acional y luego llevadas a escena por el Teatro $\mathrm{N}$ acional Chileno, con dirección de Rodrigo Pérez y Raúl 0 sorio, en 1995 y 1996, respectivamente, hasta las cinco nuevas obras de autoría individual estrenadas por el dramaturgo durante el primer semestre de la temporada 2006 -El teatro, la escena secreta, dirección de Raúl $\mathrm{O}$ sorio, Teatro $\mathrm{N}$ acional Chileno; La cruzada de los niños, dirección de M acarena Baeza, Laboratorio Teatral de la Escuela deTeatro de la U niversidad Católica; Wittgenstein, el último filósofo, dirección de Angela Cabezas, Colectivo Arte Facto; D ecapitation, dirección de Jesús Barranco, compañías Blenamiboá y EI Tinglao; y El Licenciado Vidriera o el loco de Cervantes, dirección de Julio Pincheira- , se caracteriza - retomando el esquema propuesto para la primera etapa- por tres aspectos fundamentales: el marco político y 
cultural dentro del cual el teatro del autor se reinstala en la vida pública chilena, la reelaboración de su lugar y quehacer al interior del campo teatral nacional, y la recuperación y profundización que en ese contexto hace de sus principales proyectos poéticos y discursivos.

En el país, M arco Antonio de la Parra se reposiciona en la escena pública nacional, hacia mediados de los años noventa, como parte de aquella generación de chilenos que tras oponerse - disidente, resistente, contestataria o refractariamente- a la dictadura militar, gradual y permanentemente se va a mover entre posiciones más próximas o más críticas respecto del proceso de redemocratización política, económica, social y cultural iniciado el 11 de marzo de 1990 y conducido por la Concertación.

En el teatro, el autor comparte el escenario posdictatorial con otros dramaturgos que década tras década también han acompañado en y con sus obras el devenir nacional, como Jorge D íaz (La paloma y el espino, 1957; El velero en la botella, 1962; Toda esta larga noche, 1976; Dicen que la distancia es el olvido, 1985; La cicatriz, 1996; Fanfarria para marionetas, 2001), Juan Radrigán (Testimonio de las muertes de Sabina, 1979; Pueblo del mal amor, 1986; El encuentramiento, 1995; Esperpentosrabiosamenteinmortales, 2002) y Ramón Griffero (Re cuerdos del hombre con su tortuga, 1983; Río abajo, 1995; Tus deseos en fragmentos, 2003); y con directores, actores y diseñadores que luego de superado el esquema oficialismo/oposición dentro del que nacieron a la vida artística, reformulan la labor de sus compañías de cara a la nueva situación del país, como Teatro Fin de Siglo de Ramón Griffero (Cinema-U toppia, 1985/2000; Extasis, 1993/2004; Tus deseos en fragmentos, 2003), Gran Circo Teatro de Andrés Pérez (L a negra E ster, 1988; El desquite, 1995; La huida, 2001) y Teatro La M emoria de Alfredo Castro (La manzana de Adán, 1989; Los días tuertos, 1994; M ano de obra, 2003), entre otras agrupaciones.

Todos o la mayoría de ellos -junto a muchos más-, de una u otra forma, en el texto y/o en la escena, tienden a tematizar una época confusa, tensada por profundas transformaciones socioculturales y radicalmente escéptica respecto de una posible fusión o síntesis trascendente o humanizadora entre los proyectos individuales y colectivos; situando de paso su práctica teatral, más que en el ámbito tradicional del "arte", en el campo de la producción cultural, desdibujándose así las habituales fronteras entre estética y política en favor de un continuo significante que desde la cultura interviene (en) la sociedad. Por ejemplo, a propósito de un posible vínculo entre los discursos histórico y artístico, $\mathrm{M}$ arco Antonio de la Parra señalaría:

En este país se ha quitado la emoción de la historia, y ésta, sobre todo la cercana, ha sido descrita de un modo tan sicótico que hay que trabajarla de nuevo 
para que pueda ser emocional mente recibida por un público ideológicamente heterogéneo" (cit. por Guerrero, 2001: 68).

En el panorama posdictatorial, por una parte, operaciones estéticas y políticas como ésa u otras, mayoritariamente son llevadas a cabo por el dramaturgo dentro 0 en las cercanías de la institucionalidad y/u oficialidad cultural nacional y sus vínculos con las esferas internacionales - a diferencia de su primera producción, la que circuló por canales independientes y de oposición-; por otra parte, y quizás por lo mismo, en este nuevo contexto el autor instala una voz protagónica y a veces un rol de liderazgo dentro del campo artístico y cultural chileno - también a diferencia de los primeros años, cuando sólo gradualmente se le fueron abriendo ciertos espacios. D esde esa institucionalidad, su más re ciente teatro igual se abre hacia otros registros, transitando por lo independiente, lo comercial y lo experimental, y por los múltiples pliegues en que éstos, a veces confusa y/o contradictoriamente, suelen fusionarse en el C hile actual, cuyos órdenes son permanentemente reformulados según las necesidades del mercado.

Por ejemplo, tras dejar su cargo en la Embajada deC hileen España, al regre sar al país el autor es seleccionado cinco veces en la M uestra de D ramaturgia $\mathrm{N}$ acional, la iniciativa teatral más emblemática en materia de políticas culturales gubernamentales durante el período de redemocratización - 0 felia o la madremuerta en 1995, La pequeña historia deChileen 1996, La tierra insomneo la puta madreen 1998, La vida privada en 1999 y Las costureras en 2002-, a la vez que participa como jurado en otras versiones del mismo evento estatal. Dicha muestra, junto con fomentar la emergencia de nuevos autores y obras, resulta fundamental para comenzar a reunir a dramaturgos surgidos durante la dictadura - entre otros, M arco Antonio de la Parra-, con directores aparecidos hacia la transición, cuya actividad aún no había confluido de modo significativo en la cartelera nacional; como ocurrió, por ejemplo, con el trabajo de dirección de Rodrigo Pérez para O felia o la madre muerta. La M uestra, y específicamente dicho montaje, también contribuye a la llegada del autor al Teatro $\mathrm{N}$ acional Chileno (de la Universidad de Chile), el más importante escenario teatral del país durante el siglo XX, luego de que estuviese vedado por el Gobierno militar para los dramaturgos nacionales aparecidos durante dicho período.

Paralelamente, M arco Antonio de la Parra participa en el surgimiento y de sarrollo de otras dos significativas iniciativas de convocatoria teatral: el Festival deTeatro Chileno en Pequeño Formato, surgido en 1999 y llevado a cabo durante algunos años al amparo de la U niversidad de Chile, cuyas diferentes versiones contribuyeron a la emergencia de una novísima generación de autores y directores nacionales, y el Festival de D ramaturgia Europea Contemporánea, realizado por primera vez en el año 2001 y sostenido debido al interés deemba- 
jadas e institutos culturales binacionales con sede en Santiago, el que ha concitado creciente atención como instancia de diálogo renovador para la escena teatral capitalina. A la vez, desde su quehacer como profesor de D ramaturgia en diversas escuelas de teatro, por ejemplo, de la U niversidad C atólica y de la U niversidad Finis Terrae, pero más aún a través de los innumerables talleres de dramaturgia que permanentemente ha dictado o dirigido, $M$ arco Antonio dela Parra ha gravitado desde mediados de los años noventa como principal impulsor/formador de una nueva generación de dramaturgos nacionales - muchos de los cuales, por ejemplo, mostraron sus primeros trabajos en el Festival deTeatro en Pequeño Formato creado por el autor.

Por otra parte, entre los numerosos proyectos dramatúrgicos materializados durante este último período de producción, además de los desarrollados institucionalmente, han destacado montajes experimentales como $D$ ios ha muerto (1999), dirigido por Luis U reta y llevado a escena por el Teatro La Puerta, M adrid/Sarajevo (2000), protagonizado por el autor, dirigido por D omingo 0 rtega y realizado en el marco del Proyecto Teatral Trasatlántico Chile-España, y Estamos en el aire (2001), una comedia musical dirigida por el propio autor para el Teatro $\mathrm{N}$ acional Chileno, junto a piezas que han eclipsado el circuito del así llamado "teatro comercial", como M onogamia (2000), dirigida por Alejandro Castillo, o La sexualidad secreta de los hombres (2004), dirigida por Rodrigo $M$ uñoz, las que figuran entre las más vistas en Chile durante los últimos años. En forma simultánea, mientras el autor ha mantenido una escritura relativamente autónoma, también ha trabajado al gunos proyectos de investigación y creación dramatúrgica gracias al estímulo de importantes apoyos nacionales e internacionales, como la Beca de la Fundación Andes y la Beca G uggenheim. Finalmente, desde que en $1996 \mathrm{~L}$ a pequeña historia deC hileobtuviera el Premio de la Asociación de Periodistas de Espectáculos a M ejor D ramaturgia y M ejor M ontaje, y desde que al año siguiente, 1997, M arco Antonio de la Parra fuese incorporado como M iembro de $\mathrm{N}$ úmero a la Academia Chilena de Bellas Artes del Instituto de Chile, los reconocimientos oficiales dentro y fuera del país se han sucedido destacando, entre los más recientes, el Premio M ax de las Artes Escénicas por su Trayectoria y C ontribución al Teatro H ispanoamericano, otorgado en España el 2003; el Premio del Consejo N acional del Libro y la Lectura a la M ejor O bra Teatral Inédita del 2004, recibido en Chile por Australia; y el Premio Saulo Benavente al M ejor Espectáculo Extranjero presentado en Bue nos Aires durante el 2004, obtenido por La secreta obscenidad de cada día, reestrenada ese año en Chiley con giras a diversos países, con actuación y dirección del autor, con motivo del vigésimo aniversario del debut de la pieza.

En su dramaturgia, M arco Antonio de la Parra, a partir del año 1994, claramente recupera, reordena y profundiza, en el marco de la posdictadura, los tres 
proyectos de investigación intuiti vamente perfilados durante su primer período deproducción teatral (dictadura) y programáticamente puestos en jaquedurante su segunda etapa de quehacer escénico (transición). Así, al reeditar en La pequeña historia de Chile (1994) su revisión de la historia e identidad nacional, proyecto iniciado en 1978 con Lo crudo, lo cocido, lo podrido y que continuará, por ejemplo, en Las costureras (2000), el autor ahora particulariza su gesto al mantener en el centro de su mirada a seres humanos y roles sociales tan fundamentales para el andamiaje del país como secundarizados y subordinados por éste, como garzones, profesores y costureras, cuyo quehacer y anónima contribución a los proyectos de construcción y desarrollo nacional invariablementeha guardado y sigue guardando relación con el beneficio, lucimiento o disfrute de otros. Por otra parte, al retomar el asedio a la subjetividad de la clase media chilena finisecular en EI continentenegro (1994), iniciado en 1988 con Infielesy continuado, por ejemplo, en La familia (1999) y M onogamia (2000), el dramaturgo ahora amplía su indagación al incluir en ésta a la más nueva generación de jóvenes-adultos chilenos, explorando puntos de encuentro y líneas de fuga, tensiones y acoplamientos, entre aquellos que, construyendo sus vidas durante la dictadura, por acción u omisión, dieron al país su fisonomía actual, y los hijos de éstos, quienes deben enfrentar y resolver el tránsito hacia su adultez como correlato a la posdictadura y a la consolidación del modelo de país configurado por sus padres y heredado de ellos. Por último, al insistir en 0 felia o la madre muerta (1994) en su apropiación y resemantización de grandesíconos culturales occidentales, gesto inaugurado en 1975 con M atatangos, disparen sobre EI zorzal y profundizado en este tercer período en L a puta madreo la tierra insomne o La O restiada deChile(1997), M adrid/Sarajevo (1999) y Wittgenstein, el último filósofo (2004), entre muchas otras piezas, el autor finalmente comienza a sintetizar equilibradamente al consumidor cultural nacional globalizado y al productor cultural posmoderno que lo habitan, manejando diversos repertorios y códigos-nacionalesy extranjeros, cultos y masivos, identitariosy sexuales, etc.y nutriéndose de múltiples soportes y registros - lingüísticos y literarios, visuales y audiovisuales, teóricos y tecnológicos, etc.-, entre otros recursos, con lo cual primero, propone una mirada permanentemente renovada sobre el país en diálogo con el orden mundial, a la vez que revisa el patrimonio cultural internacional desde la particularidad nacional y, segundo, se posiciona, desde Chile y Latinoamérica, como activo promotor de la investigación en torno a las posibilidades de la dramaturgia y el arte escénico en el circuito internacional y de cara al siglo XXI.

Tal como había ocurrido con el primer teatro de M arco Antonio de la Parra, este reordenamiento poético no supone una distinción rígida al interior de su producción y sólo vuelve a sugerir ciertos énfasis, siempre movedizos, que sin 
embargo se habían esfumado durante su segunda etapa de quehacer escénico. Por lo tanto, el ejercicio de apropiación y reescritura que es 0 felia o la madre muerta, además del ajuste de cuentas con la tragedia shakespereana y la tradición androcéntrica al reivindicar el protagonismo de la heroína desplazada y casi invisibilizada en/por $\mathrm{H}$ amlet, también constituyó, como los comentarios del momento lo señalaron, una reflexión acerca de aquella juventud chilena de los noventa que inconscientemente había hecho carne largos procesos de deterioro familiar y nacional, social y cultural, sobre los cuales faltaban y aún faltan explicaciones y reconocimientos honestos y verdaderos; configurándose así una generación subsidiaria del mundo y los dramas paternos (M orel, 1995-1996), que padecía en su intento por instalar una versión propia y/o diferente de los hechos - expresado esto incluso en forma aparentemente tan personal e/o indirecta como la anorexia de la protagonista (Pérez, 1995-1996). D el mismo modo, en otros casos igualmente signados por la resemantización del patrimonio cultural, como La puta madre o L a O restiada de C hile, o bien caracterizados por la revisión de la historia e identidad nacional, como La pequeña historia de Chile, en los que la atención pareciera concentrarse en macro procesos sociales, éstos son examinados en función de su impacto sobre la vida privada y la subjetividad delosindividuos, para desde ahí cuestionar, por ejemplo, la posibilidad de contar aún con, 0 de construir una, identidad común o sentido de pertenencia, un concepto o ethos fundador de/para la convivencia (Serrano, 1995); a la vez que las dimensiones individuales en las que se configura la realidad interior de los sujetos, por ejemplo, la imaginación y el deseo, el sueño y la pesadilla, son trasladadas a un plano de experiencia doblemente colectiva: por la historia nacional y el contexto internacional comunes a los que esta dramaturgia está apelando y por la experiencia teatral -y cívica- concreta a la que está dando vida (Valdés, 2000).

Así, la pregunta ¿de qué se habla cuando se habla - hoy y en el mundo de hoy- deC hile?, aunque pudo aparecer como el impulso más evidente para obras como La pequeña historia de Chile, ha terminado convocando a la mayor parte dela producción escrita, estrenada o publicada, por M arco Antonio de la Parra durante sus treinta años de actividad escénica y en particular durante este último período de su obra. En palabras del autor: "El viejo tema de la identidad, que tanto nos duele. Chile como región en duelo constante que vive la modernización como un permanente dejar de ser, sin saber bien quién se es realmente" (1995c: 8). Y en su afán por escudriñar en forma siempre renovada en dicha problemática, ha ido actualizando su exploración de la dinámica y específica subjetividad, intimidad y cotidianidad de los individuos de clase media sobre cuyas almas y cuerpos, hacia el final del siglo XX e inicios del XXI, han dejado profundas huellas $y / 0$ heridas en los intensos procesos históricos, políticos, eco- 
nómicos, sociales y culturales experimentados por el país y el mundo durante las últimas décadas.

D esde esa perspectiva, buena parte de las obras producidas durante esta tercera etapa han sido leídas por la crítica como un abordaje a la dramaticidad desolada de fin de milenio, la que configuraría un espacio mental y emocional, individual y social, del que emergería un casi sujeto, fal to de señas de identidad y en extremo vulnerable, con el deseo arruinado, sin ideología, ética ni imaginario definidos. Frentea dicho panorama, el autor asumiría el desafío ético y poé tico de indagar en la estructura profunda de la memoria cultural y de la historia simbólica para desde ahí examinar las nuevas formas de cautividad, apostando por la dramaturgia y el teatro como vehículos para evidenciar, comunicar e incluso exorcizar aquellas fuentes de tensión tan decisivas como naturalizadas en el entramado sociocultural contemporáneo (0 Icoz, 1999). En este intento por poner la experiencia estética al servicio de una verdad desesperada, al dramaturgo le resultaría productivo, por una parte, el énfasis puesto en las mujeres y lo femenino como protagonistas de mucho de su teatro más reciente, fundamentalmente por el reconocimiento de su configuración histórica-simbólica como cuerpo cautivo y discurso dañado $(0 \mid \mathrm{coz}, 2000)$ y, por otra parte, el privilegio otorgado a la dramaticidad inscrita en los cuerpos-insomnes, catatónicos, anoréxicos, bulímicos, fármaco-dependientes, alcohólicos, drogadictos, transformados, intervenidos, manipulados, etc.-, básicamente como producto de una lucha por la sobrevivencia cotidiana en la que se confía mayoritariamente en la corporalidad como camino para encontrar o rescatar aquello que llene el vacío existencial contemporáneo, siendo estosmismos cuerpos los primeros en recibir el devastador efecto del permanente fracaso de dicha apuesta (H urtado, 2000).

Formalmente, si en su primera dramaturgia el autor invitaba a la escena a soportar lo que podía construirse a partir de y en torno a la escritura/palabra teatral, como ocurría en La secreta obscenidad de cada día (1984), y en el segundo período de su obra más bien exigía a la escena completar lo sugerido por el texto, por ejemplo, en Telémaco/Subeuropa o el padre ausente (1993), en esta última etapa de su producción el dramaturgo crecientementehaido exigiendo a la escena liberar lo contenido en esta densa escritura/ palabra teatral, ya sea en vertiginosas comedias como M onogamia (2000), complejos dramas como Wittgenstén, el último filósofo (2004) o crudos comentarios sociopolíticos como D ecapitation (2004).

En síntesis, con una producción dramatúrgica y teatral extensa y compleja, que siempre ha apelado al teatro como entretención y reflexión, y que se ha multiplicado casi con la misma intensidad con la que se ha renovado y ha tratado de empujar los límites del arte teatral, M arco Antonio de la Parra se ha movido durante treinta años entre el éxito de público, los el ogios de la crítica, el 
reconocimiento de los pares y la valoración de los estudiosos, dentro y fuera de Chile, en buena medida como atento observador de los tiempos y espacios por los que ha transitado y sensible a los espíritus de época que lo han acompañado, para así proponer una mirada teatral que participa de su momento histórico a través de diversas y complejas formas y niveles, aunque no para ofrecer un modelo acucioso de reproducción ni de interpretación dela realidad sino para ape lar a reservas de experiencia, conocimiento, memoria einconsciente, entreotras, compartidas por el autor, los personajes y sus lectores, los actores, directores y diseñadores y sus espectadores, y que son las que finalmente han validado y potenciado esta dramaturgia'.

\section{REFERENCIAS BIBLIO GRAFICAS}

D ela Parra, M arco Antonio. 1983. Teatro: Lo crudo, lo cocido, lo podrido / M atatangos, disparen sobreEl zorzal. Santiago, Chile: N acimiento.

- - - . 1988. O bscenamente (in)fiel o una personal crónica de mi prehistoria dramatúrgica / La secreta obscenidad de cada día / Infieles. Santiago, C hile: Planeta.

- - - . 1990. King Kong Palace o el exilio deTarzán / D ostoi evski va a la playa. Santiago, C hile: Pehuén.

- - - 1992. El padre muerto. M enoría: Ediciones Premio Borne

- - . 1994a. Tristán el solda. Valladolid: Ediciones Premio C aja España.

1994b. D édalus en el vientre de la bestia o D édalus/Subamérica, Apuntes N 0 107.

- - - . 1994c. "Testimonio", en Elba Andrade y Walter Fuentes (eds.), Teatro y dictadura en Chile (antología crítica). Santiago, Chile: D ocumentas, pp. 33-36.

- - - . 1994d. "El retorno del texto", Apuntes N 108, pp. 94-95.

- - - . 1995a. Cartas a un joven dramaturgo. Santiago, Chile: D olmen.

- - - 1995b. La pequeña historia de Chile, Apuntes $\mathrm{N} \cong 109$

- - - . 1995c. "Asignatura pendiente", Apuntes N 109, pp. 8-9.

- - - . 1995d. "Prólogo: Por qué hay que leer a G ustavo M eza", en Gustavo M eza M urmuraciones acerca de la muertedeun juez y otras dos murmuraciones. Santiago, Chile: Lom, pp. 5-7.

- - - . 1998. Teatro mutilado de Chile: Telémaco/Subeuropa o el padre ausente / La tierra insomne o la puta madre. Santiago, Chile: D olmen.

${ }^{1} \mathrm{Si}$ M arco Antonio de la Parra de al gunaforma cerró su primer y fundacional período de actividad teatral con esa autobiografía profesional que es 0 bscenamente (in)fiel o una personal crónica de mi prehistoria dramatúrgica (Santiago, Planeta, 1988), y luego coronó la superación de su segunda y expe rimental etapa de quehacer escénico con esa reflexión profesional queesCartasa un joven dramaturgo (Santiago, D olmen, 1995), entonces quizás pueda decirse que aún está pendiente un trabajo que testimonie el trayecto recorrido durante estetercer período de producción teatral y, por quéno, que eventual mente teorice sobre el arte escénico a partir de la experiencia y el conocimiento acumulados durante tres décadas de incesante trabajo como dramaturgo y hombre de teatro. 
- - - 1999. H eroína, teatro repleto de mujeres H eroína / H éroe/ El continente negro / Lucrecia \& Judith / 0 felia o la madre muerta / La vida privada. Santiago, Chile: Cuarto Propio.

Díaz-O rtiz, 0 scar. 1996. “M arco Antonio dela Parra: M atatangosy la resemantización de su causa ausente", Latin American Theatre Review N²9, 2, pp. 43-60.

Guerrero, Eduardo. 2001. "Entrevista con M arco Antonio de la Parra", Acto único: D ramaturgos en escena, Santiago: Ril-U niversidad FinisTerrae, pp. 61-74.

H urtado, M aría de la Luz. 1992. "U na ritualidad grotesca y perversa”, en Teatro chile no contemporáneo (antología), M adrid: Fondo de Cultura Económica-Centro de D ocumentación Teatral del M inisterio de Cultura de España, pp. 801-806.

- - - 2000. “C hile, H eroína: teatro repleto de mujeres", Cel cit N os 13-14, pp. 3237

M orel, Consuelo. 1995-1996. "O felia: La imposibilidad de recibir del mundo externo", Apuntes N ㅇ 110, pp. 26-28.

O Icoz, N ieves. 1999. "Prólogo: Recado del dolor", en M arco Antonio de la Parra, H eroína, teatro repleto de mujeres. H eroína / H éroe/ El continenten egro / Lucrecia \& Judith / O felia o la madre muerta / La vida privada. Santiago, Chile: Cuarto Propio, pp. 9-34.

- - - 2000. "M arco Antonio de la Parra, La mutilación: La puta madre", Teatro de mujer y culturas del movimiento en América Latina. Santiago, Chile: Cuarto Propio, pp. 205-216.

Pérez, Rodrigo. 1995-1996. "O felia: Aquí se asesina a la juventud", A puntes $\mathrm{N}$ ㅇ 110 pp. 21-23.

Piña, Juan Andrés. 1983. "Prólogo: M arco Antonio de la Parra, el teatro del ritual y del desecho", en M arco Antonio de la Parra, Teatro: Lo crudo, lo cocido, lo podrido / M atatangos. Santiago, Chile: N acimiento, pp. 7-23.

- - - 1998a. "D os obras, un autor, un estilo: Lo crudo, lo cocido, lo podrido y $M$ atatangos" (1 $1^{\text {ra }}$ ed. en M ensaje, agosto de 1978), 20 años de teatro chileno, 19761996. Santiago, Chile: Ril, pp. 59-64.

- - . 1998b. "El deseo de toda ciudadana, una sugerente ambigüedad" (1 $1^{\text {ra }}$ ed. en Apsi, marzo de 1987), 20 años de teatro chileno, 1976-1996. Santiago, Chile: Ril, pp. 65-67.

Seda, Laurietz. 2000. "¿Q uién vigila a los vigilantes? La secreta obscenidad de cada día de M arco Antonio de la Parra", en H eidrun Adler y George Woodyard (eds.), Resistencia y poder: Teatro en Chile. M adrid: Vervuert-Iberoamericana, pp. 89-98.

Sentis, Verónica. 1998. "M odos de la censura durante la dictadura militar chilena: Lo crudo, lo cocido, lo podrido; una experiencia concreta", La Escalera N ㅇ 8, pp. 179186.

Serrano, Sol. 1995. "D e los padres de la patria a la patria de nuestros padres", A puntes $N^{\circ} 109$, pp. 10-12.

U libarri, Luisa. 1999. "La secreta obscenidad de cada día" (1ª ed. en La Epoca, 1987), en M aría Teresa Z egers, 25 años de teatro en Chile. Santiago, Chile: M inisterio de Educación, p. 246.

Valdés, Adriana. 2000. "Sobre La puta madre (apuntes de una diletante)", Teatrae N ${ }^{\circ}$ 2, pp. 62-67. 
Vidal, H ernán. 1982. "Cultura nacional y teatro profesional reciente", en M aría de la Luz H urtado, C arlos $\mathrm{O}$ chsenius y H ernán Vidal (eds.), Teatro chileno de la crisis institucional, 1973-1980 (antología crítica). M inneapolis-Santiago: U niversity of M innesota-C eneca, pp. 82-88. 